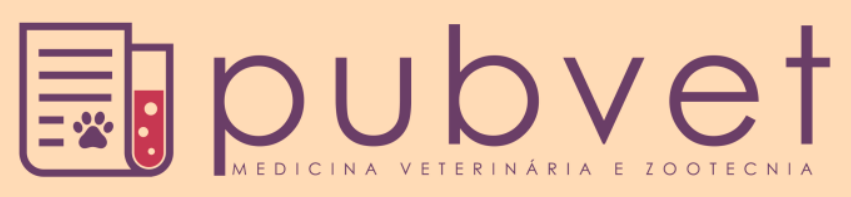

https://doi.org/10.22256/pubvet.v12n5a91.1-9

\title{
Ciclagem de nutrientes em ecossistemas de pastagens tropicais
}

\author{
Marcondes de Sá Souza ${ }^{\ominus 1}$, Alexandre Maniçoba da Rosa Ferraz Jardim ${ }^{1 *}{ }^{\bullet}$, George do \\ Nascimento Araújo Júnior ${ }^{1}$, José Raliuson Inácio Silva ${ }^{1}{ }^{\ominus}$, Maurício Luiz de Mello \\ Vieira Leite $^{2} \theta$, Vicente Imbroisi Teixeira ${ }^{2} \theta$, Thieres George Freire da Silva ${ }^{2} \theta$ \\ ${ }^{I}$ Mestrando em Produção Vegetal, Universidade Federal Rural de Pernambuco, Unidade Acadêmica de Serra Talhada. Serra Talhada - PE \\ Brasil.E-mail: marcondes.sa33@gmail.com; georgejunior91@hotmail.com; raliuson.agro@gmail.com \\ ${ }^{2}$ Professor da Universidade Federal Rural de Pernambuco, Unidade Acadêmica de Serra Talhada. Serra Talhada - PE Brasil. E-mail: \\ nopalea21@yahoo.com.br; vicente ufrpe@hotmail.com; thigeoprofissional@hotmail.com \\ *Autor para correspondência, E-mail: alexandremrfj@gmail.com
}

RESUMO. A degradação das pastagens brasileiras tem sido um problema crescente, principalmente em regiões de fronteira agrícola, onde as práticas de manejo adotadas são inadequadas, causando um desequilíbrio neste ecossistema. Práticas de manejo que favorecem a ciclagem de nutrientes aparecem neste cenário como uma alternativa para a recuperação de pastagens degradadas. Se tratando de pastagens, os maiores reservatórios de nitrogênio $(\mathrm{N})$ e carbono $(\mathrm{C})$ são a atmosfera, o solo, as espécies vegetais e os animais em pastejo, sendo que a dinâmica desses nutrientes é controlada por fatores bióticos e abióticos. A serapilheira e os excrementos animais representam as principais vias de retorno dos nutrientes ao ecossistema através da decomposição por microrganismos. A utilização de espécies leguminosas consorciadas com pastagens é uma boa estratégia para incrementar o conteúdo de nitrogênio no solo, minimizando custos com adubação nitrogenada, além de melhorar a qualidade da serapilheira.

Palavras-chave: excreta animal, nitrogênio, serapilheira

\section{Nutrient cycling in tropical pasture ecosystems}

\begin{abstract}
The degradation of Brazilian pastures has been an increasing problem, especially in agricultural frontier regions, where the management practices adopted are inadequate, causing an imbalance in this ecosystem. Management practices that favor nutrient cycling appear in this scenario as an alternative for the recovery of degraded pastures. In the case of pastures, the largest reservoirs of nitrogen $(\mathrm{N})$ and carbon $(\mathrm{C})$ are the atmosphere, soil, plant species and grazing animals, being that the dynamics of these nutrients is controlled by biotic and abiotic factors. The litter and the animal excreta represent the main routes of return of the nutrients to the ecosystem through the decomposition by microorganisms. The use of legume species intercropped with pasture is a good strategy to increase soil nitrogen content, minimizing costs with nitrogen fertilization, in addition to improving the quality of the litter.
\end{abstract}

Keywords: animal excreta, nitrogen, litter

\section{Ciclo de nutrientes en ecosistemas de pastos tropicales}

RESUMEN. La degradación de los pastos brasileños ha sido un problema creciente, principalmente en regiones de frontera agrícola, donde las prácticas de manejo adoptadas son inadecuadas, causando un desequilibrio en este ecosistema. Las prácticas de manejo que favorecen el ciclo de nutrientes aparecen en este escenario como una alternativa para la recuperación de pastos degradados. Tratándose de pastajes, los depósitos más grandes 
de nitrógeno $(\mathrm{N})$ y carbón $(\mathrm{C})$ son la atmósfera, el suelo, las especies vegetales y los animales en pastoreo, siendo que la dinámica de esos nutrientes es controlada por factores bióticos y abióticos. El humus y los excrementos animales representan las principales vías de retorno de los nutrientes al ecosistema a través de la descomposición por microorganismos. La utilización de especies leguminosas consorciadas con pastos es una buena estrategia para incrementar el contenido de nitrógeno en el suelo, minimizando costos con fertilización nitrogenada, además de mejorar la calidad del humus.

Palabras clave: excreta animal, nitrógeno, humus

\section{Introdução}

A ciclagem de nutrientes é entendida como o fluxo ou a movimentação destes nos diferentes compartimentos do ecossistema de pastagem (solo-planta-animal-atmosfera). A disponibilidade dos nutrientes está em função de alterações moleculares com a finalidade de serem utilizados pela microbiota do solo, espécies vegetais e animais dentro da pastagem (Dubeux Júnior et al., 2006). Este processo é também denominado de ciclo biogeoquímico.

O fluxo de nutrientes na pastagem é regulado por fatores bióticos e abióticos. Quanto ao último, vale ressaltar a importância da umidade neste processo, tendo em vista que a disponibilidade de água no solo é responsável pela maior ou menor atuação da atividade microbiana, bem como pela translocação e absorção de nutrientes pelos vegetais (Troeh \& Thompson, 2007). Neste contexto, os fatores bióticos que se destacam, dizem respeito às plantas e as formas como elas absorvem os íons presentes na solução do solo, aos microrganismos edáficos que atuam principalmente na decomposição da matéria orgânica, e aos animais em pastejo.

Além de se considerar as entradas e saídas (perdas) dos elementos num ecossistema para o estudo dos ciclos biogeoquímicos, deve-se levar em conta como esses nutrientes retornam ao ambiente. Neste sentido, os resíduos vegetais e animais depositados sobre o solo numa pastagem, são considerados as principais vias de retorno de nutrientes ao sistema (Vendramini et al., 2007).

É de fundamental importância conhecer esse processo e tudo que implica no seu funcionamento, pois segundo Dias-Filho (2014), estima-se que mais de $70 \%$ das pastagens brasileiras encontra-se em contínuo processo degradativo, principalmente nas regiões de expansão agropecuária, afetando o potencial produtivo de um dos maiores produtores e exportadores de carne bovina do mundo. Dentre as principais causas que aceleram o processo de degradação deste ecossistema, destaca-se a intervenção antropogênica com práticas de manejo inadequadas como, por exemplo, adubação deficiente e altas taxas de lotação animal (Dias-Filho, 2006).

Frente a esta problemática, buscam-se estratégias de manejo que minimizem a degradação, bem como melhorem a eficiência da circulação dos nutrientes na pastagem. Portanto, nesta revisão, objetiva-se discutir sobre a dinâmica dos nutrientes em pastagens tropicais, as principais vias de retorno de nutrientes e a utilização de leguminosas consorciadas com gramíneas forrageiras como prática alternativa para proporcionar melhor ciclagem de nutrientes.

\section{Dinâmica dos nutrientes ( $\mathrm{N}$ e C) nas pastagens}

A atmosfera, o solo, as espécies vegetais e os animais em pastejo são considerados os maiores compartimentos de nitrogênio $(\mathrm{N})$ dentro de ecossistemas de pastagens, onde fatores bióticos (vegetação, animais e microrganismos) e abióticos (umidade e energia radiante) são responsáveis pela sua movimentação nos diferentes compartimentos (Dubeux Júnior et al., 2007). Na maioria das terras agrícolas do mundo, o nitrogênio é considerado o nutriente mais limitante para as culturas, em razão de sua baixa disponibilidade em regiões tropicais, contribuindo para o aumento da degradação de pastagens (Vendramini et al., 2007).

Apesar da atmosfera conter a maior parte do nitrogênio presente no planeta em comparação com todos os outros compartimentos (Vendramini et al., 2014), a sua contribuição no fornecimento de nitrogênio para os cultivos agrícolas, inclusive pastagens cultivadas, via deposição atmosférica, é praticamente insignificante (Dubeux Júnior et al., 2006).

O nitrogênio pode ser introduzido nos ecossistemas de pastagens de forma natural e não natural. No primeiro caso, ele é incorporado no sistema, dentre outras formas, através de fixação biológica, precipitação pluvial e deposição atmosférica. Como também, de forma alternativa, a sua entrada pode ocorrer por meio da fertilização 
e da suplementação animal, ou seja, de forma não natural (Dias-Filho, 2006).

No entanto, durante os processos que fazem parte do ciclo de nitrogênio, podem, também, ocorrer perdas deste nutriente no sistema (Figura 1). Além das colheitas, as quais são responsáveis por exportar grandes quantidades dos nutrientes contidos nos tecidos vegetais, é interessante considerar também outros fatores que interferem diretamente na disponibilidade dos nutrientes e que podem acarretar em perdas expressivas de nitrogênio, como a erosão, a lixiviação (principalmente na forma de nitrato $\left[\mathrm{NO}_{3}{ }^{-}\right] \mathrm{em}$ solos permeáveis) e a volatilização (amônia $\left[\mathrm{NH}_{3}\right]$, nitrogênio molecular $\left[\mathrm{N}_{2}\right]$ e óxidos de nitrogênio) (Troeh \& Thompson, 2007). Assefa et al. (2017) perceberam que a remoção da vegetação natural resultou em diminuição considerável do estoque de carbono (C) e de nitrogênio, por conta de processos erosivos; porém as áreas reflorestadas com eucalipto e as áreas de exclusão (antigas pastagens) mostraram potencial de recuperação parcial dos estoques desses nutrientes em camadas superficiais.

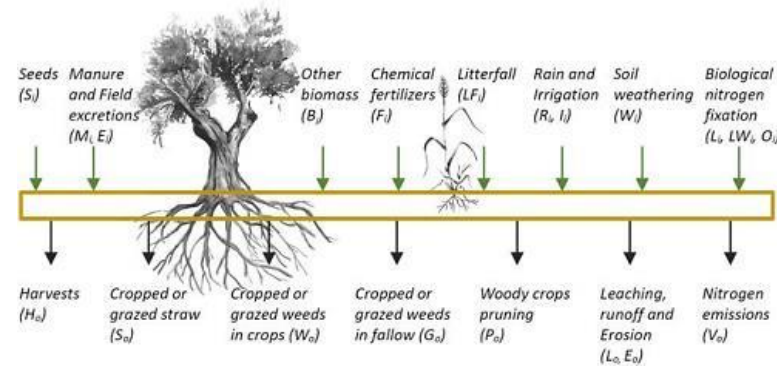

Figura 1. Formas de entrada (setas verdes) e de saída (setas pretas) dos nutrientes em um ecossistema. Carmo et al (2017).

Os nutrientes com alta mobilidade no solo, a exemplo do nitrogênio e potássio $(\mathrm{K})$, são mais facilmente lixiviados, principalmente em solos mais profundos, sendo translocados pela água da chuva, dificultando o acesso do sistema radicular de muitas culturas aos nutrientes. Enquanto que a volatilização, processo geralmente observado com o nitrogênio, ocorre por intermédio da desnitrificação (Teixeira, 2010). Em relação às perdas por exportação de nutrientes ingeridos, sabe-se que estas são maiores em sistemas de produção de leite em comparação com sistemas de produção de carne, tendo em vista que o leite retirado dos animais implica na saída irreversível dos nutrientes (Balbinot Junior et al., 2009).

Dentre os principais fatores que interferem na dinâmica do nitrogênio, merece destaque a relação carbono:nitrogênio (C:N) da matéria orgânica do solo (MOS), a qual determina a velocidade de decomposição, como também, interfere na mineralização ou imobilização do nitrogênio por parte da microbiota do solo (Figura 2). Troeh \& Thompson (2007) explicaram que quando a atividade microbiana atua sobre a decomposição da MOS, ocorre a liberação de formas inorgânicas de elementos, processo este conhecido como mineralização. Porém, quando íons inorgânicos são convertidos em formas orgânicas, denominase imobilização (Troeh \& Thompson, 2007). Esses autores ainda afirmaram que boa parte da imobilização do nitrogênio ocorre devido ao fato dos microrganismos do solo necessitarem de nitrogênio para sintetizarem proteínas, chegandose a conclusão que a introdução de materiais decomponíveis no solo com baixas concentrações deste nutriente, acarretará em maior imobilização do mesmo.

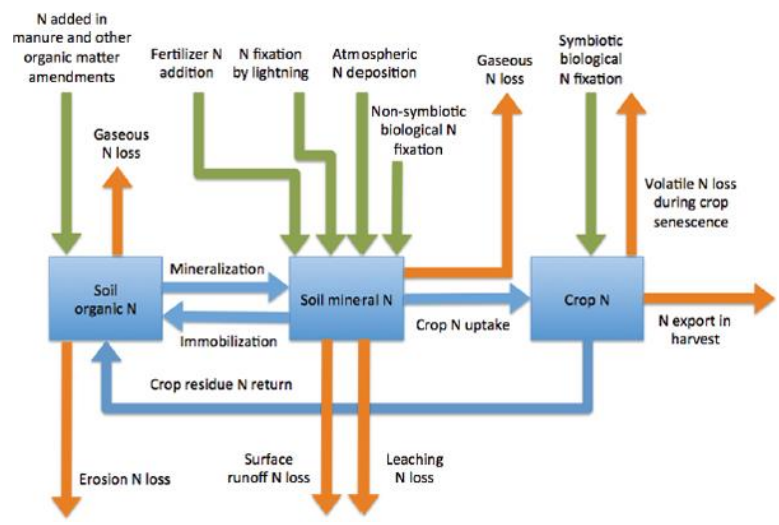

Figura 2. Principais estoques e fluxos do nitrogênio em um sistema de cultivo. Nesheim et al. (2015).

De acordo com Dubeux Júnior et al. (2007) a MOS, apesar de ser o maior reservatório de nutrientes, não pode ser considerada a principal fonte nutricional imediata para os vegetais por conta da sua baixa taxa de mineralização. Mais de $95 \%$ do nitrogênio do solo está ligado à matéria orgânica. No entanto, ela disponibiliza entre 10 e $40 \mathrm{~kg} \mathrm{ha}^{-1}$ ano $^{-1}$ de nitrogênio, para cada $1 \%$ de MO do solo, o que é considerado insuficiente para as altas exigências de gramíneas forrageiras tropicais (Costa et al., 2006). Faz-se necessário conhecer os processos de decomposição e mineralização dos distintos resíduos que darão origem a MOS, a fim de que estes possam ser inseridos nos sistemas produtivos, com o objetivo de fornecer nutrientes através dos fluxos biogeoquímicos (Maluf et al., 2015).

Mundialmente, o solo é considerado o maior reservatório de carbono, contendo 
aproximadamente, mais de quatro vezes o teor de carbono presente na biomassa da comunidade vegetal e na atmosfera, atuando como fonte ou depósito de $\mathrm{CO}_{2}$ atmosférico (Assefa et al., 2017), embora a escala espacial e a profundidade de amostragem contribuam significativamente nas oscilações da quantificação do carbono orgânico do solo (Maillard et al., 2017).

As pastagens assumem um papel fundamental, tanto na movimentação, quanto no conteúdo de carbono no solo. De acordo com Braga (2006), aproximadamente $20 \%$ da circulação de carbono no planeta, e $12 \%$ do carbono estocado no solo são provenientes das pastagens. Esse autor explica que isso acontece em razão do conteúdo expressivo de MOS e sua lenta decomposição neste ecossistema.

Vários fatores contribuem de forma significativa no aumento ou diminuição nos estoques e na dinâmica do carbono no solo, dentre eles, destaca-se as mudanças no uso da terra. De acordo com Araújo et al. (2011), a conversão da floresta em pastagens de Brachiaria brizantha no bioma amazônico, aumentou significativamente os estoques de carbono no solo, principalmente nas camadas superficiais das pastagens mais antigas (10 e 20 anos de utilização), o que pode ser explicado pela contribuição do sistema radicular das gramíneas forrageiras e do maior aporte de matéria orgânica, tanto em superfície quanto em profundidade (Braga, 2006). Araújo et al. (2011) também observaram que o carbono proveniente da pastagem teve uma representatividade de $70 \%$ do carbono total em relação às áreas de floresta. No entanto, estudos realizados por Costa et al. (2009) em áreas de Mata Atlântica, pastagem bem manejada e pastagem degradada, com distintas idades de utilização no sul da Bahia, não mostraram diferença significativa no carbono estocado no solo nas três áreas. Esses autores explicam que esse comportamento está em função da variabilidade dos teores de matéria orgânica, bem como em função dos diferentes fatores que regulam a sua decomposição.

Além das mudanças no uso da terra, do desmatamento e consequente substituição da vegetação natural por áreas de pastagens, os sistemas de manejo do solo em áreas cultivadas também se destacam nas alterações da dinâmica de nutrientes. Salton et al. (2011) verificando os teores e a dinâmica do carbono em função de diferentes sistemas de manejo do solo, observaram que as pastagens apresentaram os maiores valores nas taxas de acúmulo e nos estoques de carbono em comparação com os sistemas exclusivos de lavouras anuais. Os autores atribuem esses resultados ao fato de que a grande parte do carbono armazenado nas pastagens encontra-se em subsuperfície, como também, áreas de pasto contribuem melhor que lavouras no aporte de material vegetal.

As práticas de manejo envolvidas na pastagem, como por exemplo, a intensidade de corte e o método de pastejo também apresentam grande potencial nas oscilações dos teores de carbono e nitrogênio no solo. Com base nisso, Souza et al. $\underline{(2009)}$ avaliando os efeitos de três níveis de intensidade de pastejo $(10,20$ e $40 \mathrm{~cm})$ sobre os estoques de carbono orgânico (CO) e de nitrogênio total (NT) em sistema de integração lavoura-pecuária sob plantio direto, perceberam um aumento considerável desses estoques nos tratamentos com menores intensidades de corte $(20$ e $40 \mathrm{~cm})$. Por outro lado, nos tratamentos com a menor altura de corte $(10 \mathrm{~cm})$, obteve-se drástica redução nos teores dos nutrientes, bem como redução na qualidade da MOS. Cardoso et al. (2010) puderam constatar reduções expressivas nos estoques de $\mathrm{CO}$ e carbono microbiano em pastagens nativas submetidas ao método de pastejo contínuo quando comparadas à pastagem nativa sem pastejo por 19 anos. Todavia, os estoques de nitrogênio não sofreram alterações significativas. Esses mesmos autores ainda acrescentaram que três anos sem pastejo nas pastagens nativas são insuficientes para aumentar os estoques de $\mathrm{CO}$ do solo, não havendo diferença do método de pastejo contínuo.

\section{Ciclagem de nutrientes via serapilheira}

A serapilheira refere-se à camada de resíduos depositada sobre o solo proveniente da senescência e/ou abscisão foliar de plantas que não foram consumidas pelos animais, incluindo também galhos, raízes e outras partes constituintes (Dubeux Júnior et al., 2006). Essa camada é responsável por armazenar quantidades expressivas de nutrientes (Vendramini et al., 2014), os quais retornarão ao solo por meio da decomposição efetuada por microrganismos e pela microfauna edáfica (Troeh \& Thompson, 2007). Através da decomposição, a serapilheira fornece nutrientes para o solo, os quais serão reabsorvidos pelas plantas, contribuindo para a manutenção dos ecossistemas terrestres (Silva et al., 2007), incluindo as pastagens. 
A deposição ou distribuição da serapilheira no ambiente da pastagem é mais homogênea quando comparada com os excrementos animais (Vendramini et al., 2007). No entanto, faz-se necessário levar em consideração as propriedades físico-químicas, bem como aspectos qualitativos e quantitativos da serapilheira depositada no solo, os quais estão diretamente ligados ao controle dos fluxos biogeoquímicos dos nutrientes (Dubeux Júnior et al., 2007).

A quantidade de serapilheira depositada num ambiente depende de vários fatores, bióticos e abióticos. Dentre eles, o regime de precipitação pluvial em determinada região merece destaque. Avaliações realizadas por Silva et al. (2007) em áreas de Cerrado e de transição CerradoAmazônia, constataram maior aporte de serapilheira na época seca em contraste com a época chuvosa, principalmente na área de transição. As folhas representaram a maior fração depositada em comparação aos outros constituintes vegetais. Resultados um pouco contrastantes foram observados por Andrade et al. (2008), em área de Caatinga, onde foi observada menor produção de serapilheira no fim do período seco. Os autores atribuem esses resultados ao fato de que a maioria das espécies da caatinga são caducifólias. O conhecimento dos efeitos do regime hídrico sobre a produção de serapilheira, principalmente nas regiões semiáridas, é de suma importância, tendo em vista que essas regiões apresentam distribuição irregular de chuvas, com o período seco sendo o maior durante o ano (Silva \& Rao, 2006), afetando a produção de forragem em pastagens naturais e nativas.

É interessante também verificar os aspectos qualitativos da serapilheira, uma vez que resíduos vegetais de baixa qualidade implicarão em menor proporção de nutrientes retornados ao solo por esta via. Um dos indicadores mais importantes que refletem a qualidade da serapilheira é a relação C:N. De acordo com Silva et al. (2009), plantas que apresentam altos teores de nitrogênio em sua biomassa, como as leguminosas, disponibilizam resíduos com baixa relação $\mathrm{C}: \mathrm{N}$, o que significa mais rápida decomposição e consequentemente, maior taxa de mineralização de nitrogênio para os vegetais. No entanto, segundo Carneiro et al. (2013), outros fatores, além da relação C:N, devem ser considerados na determinação das taxas de mineralização de nitrogênio, como teor de nitrogênio, de lignina, de polifenóis e as formas de nitrogênio presentes nos resíduos. Resultados obtidos por Maluf et al. (2015) mostraram que a decomposição dos restos vegetais foi significativamente influenciada pelas concentrações de nitrogênio, e as taxas de liberação dos macronutrientes, pelos teores dos mesmos nos resíduos, sendo o $\mathrm{K}$ o nutriente liberado mais rapidamente pelo fato de não ser constituinte de estruturas vegetais.

A adubação de pastagens com fertilizantes nitrogenados, apesar de ser uma prática de manejo relativamente cara e com potencial para danos ambientais, pode resultar em alterações na qualidade da serapilheira produzida. Com base nisso, Apolinário et al. (2014), testando doses de nitrogênio e distintas lotações animais na decomposição de serapilheira em pastagem de $B$. decumbens, constataram diminuição da relação $\mathrm{C}: \mathrm{N}$, bem como o aumento na taxa de decomposição juntamente com o aumento das doses de fertilização nitrogenada. Os valores das taxas obtidos foram 4,47 e $3,29 \mathrm{mg} \mathrm{g}^{-1}$ dia $^{-1}$ para os tratamentos com os níveis 300 e $0 \mathrm{~kg} \mathrm{~N} \mathrm{ha}^{-1}$ ano $^{-}$ ${ }^{1}$, respectivamente. As taxas de decomposição não sofreram efeito significativo das lotações animais, todavia houve incremento no aporte de serapilheira com as menores lotações, tendo em vista maiores sobras de forragem com menor número de animais por área.

Todos esses fatores, dentre outros, contribuem de forma direta e indireta na qualidade dos resíduos vegetais depositados sobre o solo. Isso implica em dizer que o aporte de serapilheira com baixa qualidade pode ser considerado um dos maiores contribuintes para o aumento da degradação de pastagens tropicais e subtropicais (Vendramini et al., 2014).

\section{Ciclagem de nutrientes via excreta animal}

Juntamente com a serapilheira, a excreta animal se constitui como uma das principais formas de retorno dos nutrientes para o ambiente da pastagem. Esse retorno é imprescindível para a conservação da fertilidade do solo, sendo afetado pelas práticas de manejo adotadas, como também pelos fatores ambientais que regulam $\mathrm{O}$ ecossistema (Dubeux Júnior et al., 2006). A excreta animal é responsável pelo retorno de aproximadamente 70 a 95\% dos nutrientes ingeridos pelos animais, tanto na forma de urina quanto de fezes (Balbinot Junior et al., 2009), atestando assim, a grande importância desta via de retorno na manutenção da fertilidade do solo na pastagem (igura 3). 


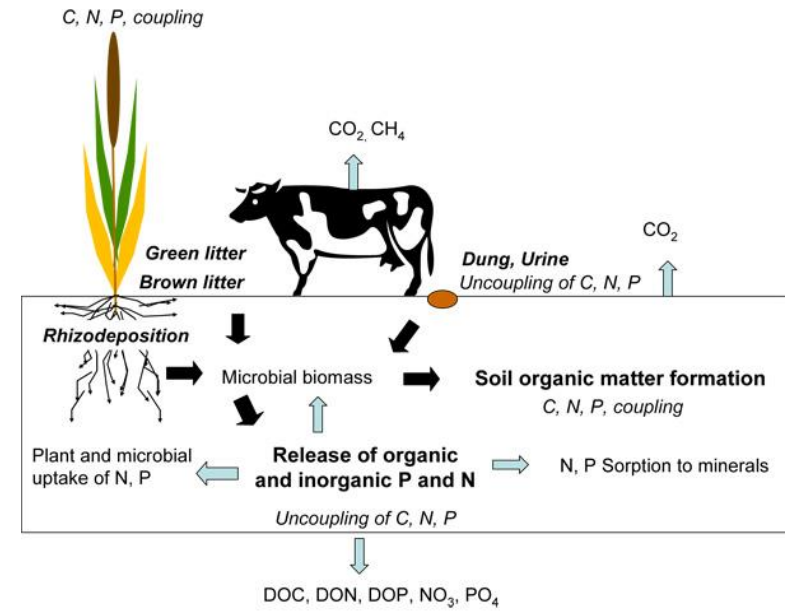

Figura 3. Principais processos que controlam os ciclos de carbono, nitrogênio e fósforo na pastagem. Rumpel et al. (2015).

Conforme detalhado por Barcellos et al. (2008) a excreta é a via mais rápida em comparação com a serapilheira, onde 50 a $80 \%$ dessa deposição ocorre através da urina. Todavia, a eficiência na ciclagem por este meio é reduzida por conta da distribuição heterogênia dos resíduos animais, cobrindo cerca de 30 a $40 \%$ da área com altas lotações, e por conta das maiores perdas por lixiviação e volatilização. Aproximadamente, 500 a $1500 \mathrm{~kg} \mathrm{ha}^{-1}$ de $\mathrm{N}$ são depositados no local da excreção. Os estoques de nitrogênio, bem como a sua distribuição pelas excretas dos animais, aumentam proporcionalmente com a qualidade da forragem, ou seja, essas variáveis são dependentes dos teores de nitrogênio na composição química do pasto e da dieta animal (Barcellos et al., 2008).

É interessante destacar também que os distintos nutrientes são distribuídos de forma diferenciada entre urina e fezes. Enquanto o sódio (Na) e o K são excretados principalmente via urina, as fezes são responsáveis por eliminar principalmente elementos como fósforo $(\mathrm{P})$, cálcio $(\mathrm{Ca})$, magnésio $(\mathrm{Mg})$ e micronutrientes, sendo que nitrogênio e enxofre (S) são liberados nas fezes e urina, a depender do teor dos mesmos na dieta animal (Saraiva, 2010).

Como discutido acima, é constatado que a distribuição espacial das excretas no ambiente da pastagem é desuniforme (Vendramini et al., 2014). Os animais em pastejo tendem a depositar seus resíduos em locais muito específicos, como por exemplo, próximo à bebedouros e sombras, resultando em diminuição da eficiência de utilização dos nutrientes retornados, ou seja, havendo maior perda de nutrientes como também, maiores concentrações de nutrientes em locais que não têm tanta importância na produção do pasto (Dubeux Júnior et al., 2014; Saraiva, 2010). Isso significa que o comportamento animal, bem como a sua preferência por locais de repouso, afetam diretamente a deposição de excretas como também, a distribuição de nutrientes, acarretando na redução da fertilidade do solo na maior parte das áreas da pastagem.

As práticas de manejo adotadas numa pastagem podem alterar significativamente a composição e o retorno dos nutrientes via excreta animal. Uma delas é a pressão de pastejo, a qual regula a quantidade de resíduo pós-pastejo. Isso significa que quanto maior a pressão de pastejo, maior a quantidade de forragem consumida, e maior a proporção de nutrientes retornada ao sistema via excreta, ou seja, menor proporção de resíduo pós-pastejo (Dubeux Júnior et al., 2006).

Saraiva (2010) avaliando o efeito de três alturas de resíduo pós-pastejo $(40,80$ e $120 \mathrm{~cm})$ de capim-elefante (Pennisetum purpureum) sobre o retorno dos nutrientes via fezes e urina, verificou que as diferentes alturas afetaram somente a proporção de nitrogênio e $\mathrm{Mg}$ nas fezes, sendo observada maior concentração dos mesmos onde houve maior consumo de forragem $(40 \mathrm{~cm})$. A deposição de nitrogênio via excreta foi de $506 \mathrm{~g} \mathrm{~N}$ $\mathrm{ha}^{-1} \mathrm{dia}^{-1}$, onde $53 \%$ foram retornados pelas fezes e $47 \%$ através da urina, apresentando, praticamente, as mesmas proporções. A urina proporcionou primordialmente o retorno de 95 e $96 \%$ referentes a $\mathrm{K}$ e Na, respectivamente. Já as fezes foram responsáveis pela deposição de 78 e $81 \%$ de $\mathrm{Ca}$ e $\mathrm{Mg}$, respectivamente. Foi observada a presença de $\mathrm{P}$ somente nas fezes. Com estes resultados pode-se constatar que o retorno de nitrogênio contribuiu, teoricamente, com uma economia equivalente a $185 \mathrm{~kg} \mathrm{~N} \mathrm{ha}^{-1} \mathrm{ano}^{-1}$. Considerando-se os principais fertilizantes nitrogenados, isso equivale a, aproximadamente, $411 \mathrm{~kg} \mathrm{ha}^{-1}$ ano $^{-1}$ e $881 \mathrm{~kg} \mathrm{ha}^{-1}$ ano $^{-1}$ de ureia e sulfato de amônio, respectivamente.

A presença das fezes, bem como a lotação animal, também são fatores considerados importantes na dinâmica de nutrientes da pastagem. Teixeira et al. (2012) estudaram os impactos das placas de fezes em relação a massa de forragem, rejeição de forragem e caracterização química de $B$. decumbens sob três lotações animais $\left(1,9,3,2\right.$ e 4,2 $\left.\mathrm{UA} \mathrm{ha}^{-1}\right)$. Foi observado que na menor lotação animal (1,9 UA ha $\left.{ }^{-1}\right)$ houve maior rejeição de forragem, isso porque os animais tiveram maior liberdade para 
selecionarem os locais específicos de pastejo. A presença das fezes fez com que houvesse maior rejeição de forragem no seu entorno, pois o gado bovino, em particular, tende a evitar o pastejo de plantas em áreas muito próximas as placas de fezes. Também foi verificado que abaixo das placas de fezes o $\mathrm{pH}$ aumentou, bem como teores de $\mathrm{P}$ e $\mathrm{K}$ no solo. No entanto, as plantas que se encontravam mais distantes das fezes mostraram menores teores de $\mathrm{P}$ em sua composição. Isso porque, como constatado por Saraiva (2010), as fezes são vias de retorno importantes de $\mathrm{P}$, porém é um nutriente que apresenta baixa mobilidade no solo (Troeh \& Thompson, 2007).

\section{Consórcio de leguminosas em pastagens}

Apesar da adubação nitrogenada apresentar um papel relevante no incremento da produtividade, como também no valor nutricional de plantas forrageiras, na minimização da degradação de pastagens, ocasionando melhorias de desempenho econômico na criação de animais (Vitor et al., 2009), a sua utilização pode ser reduzida em função de fatores ambientais e econômicos (Dubeux Júnior et al., 2006). Os resíduos vegetais produzidos pelas gramíneas tropicais, geralmente, apresentam baixa qualidade, em razão dessas pastagens serem cultivadas, em sua maioria, em ambientes de baixa fertilidade (Vendramini et al., 2007), resultando em maior imobilização e consequente diminuição da eficiência de ciclagem de nutrientes. Uma boa opção para esses problemas seria a melhoria da qualidade desses resíduos, através da utilização de espécies leguminosas (Silva et al., 2012).

A utilização de leguminosas forrageiras em consórcio com gramíneas, além de proporcionar incremento na produção de forragem e de fornecer proteína na dieta dos animais, apresenta grande potencial para fixação biológica de nitrogênio, destacando-se como alternativa para melhoria do rendimento forrageiro de espécies não leguminosas no sistema consorciado (Sadeghpour et al., 2013).

Silva et al. (2013) verificaram que a inserção de leguminosas arbustivas e arbóreas forrageiras em pastagem degradada de Brachiaria decumbens aumentou significativamente os teores de nitrogênio total da serapilheira, além de ter reduzido a relação $\mathrm{C}: \mathrm{N}$, principalmente com a utilização das espécies sabiá (Mimosa caesalpiniifolia) e gliricídia (Gliricidia sepium). Os teores de nitrogênio total encontrados na serapilheira de sabiá e gliricídia foram 12,3 e 11,4 $\mathrm{g} \mathrm{kg}^{-1}$, respectivamente. A relação $\mathrm{C}: \mathrm{N}$ na serapilheira sob leguminosas apresentou valores $50 \%$ menores em comparação a área com apenas a gramínea.

Estudos desenvolvidos por Xavier et al. (2012) verificaram que a utilização de leguminosas arbóreas e de eucalipto em sistema silvipastoril consorciados com braquiária, além de ter incrementado a deposição de serapilheira (5.038 e $3.944 \mathrm{~kg} \mathrm{ha}^{-1}$ ano $^{-1}$ para sistema silvipastoril e monocultura de braquiária, respectivamente), o retorno de nitrogênio foi maior em sistema silvipastoril em comparação com a monocultura (228 e $107 \mathrm{~kg} \mathrm{ha}^{-1} \mathrm{ano}^{-1}$, respectivamente). Esses resultados apontam para o grande potencial dos sistemas silvipastoris para melhorar a eficiência da ciclagem de nutrientes, bem como para atuar na recuperação de pastagens degradadas. Silva et al. (2012) observaram que a introdução de Calopogonium mucunoides em pastagem de $B$. decumbens proporcionou um incremento significativo na mineralização líquida anual de nitrogênio, confirmando a hipótese de que esta leguminosa é um agente acelerador da ciclagem de nutrientes.

\section{Considerações finais}

Uma das grandes marcas das pastagens tropicais e subtropicais em todo o planeta tem sido a baixa fertilidade natural dos solos. Este problema associado aos altos custos dos fertilizantes químicos, e também ao cultivo de pastagens em áreas marginais resulta na degradação destas. Por sua vez, esta degradação tem se mostrado cada vez mais crescente, inclusive no Brasil, reduzindo drasticamente a produtividade das pastagens.

Os temas discutidos nesta revisão apresentam, além dos fatores que interferem na dinâmica dos nutrientes, as práticas de manejo que podem favorecer este fluxo. Cabe aos produtores lançarem mão destas a fim de recuperarem a produtividade de suas propriedades. Além da utilização de taxas adequadas de lotação animal e da distribuição estratégica de bebedouros e cochos na pastagem, a utilização de leguminosas em consórcio com gramíneas forrageiras e de sistemas silvipastoris tem demonstrado grande contribuição na recuperação de pastagens degradadas.

Frente a esses benefícios, novas pesquisas devem ser desenvolvidas com a finalidade de criar outras estratégias de manejo que igualmente 
contribuam para a recuperação deste tão importante meio de produção, como também assegurem sua manutenção seguindo os princípios básicos de sustentabilidade, pois o meio ambiente apresenta alta sensibilidade à interferência humana.

\section{Referências bibliográficas}

Andrade, R. L., Souto, J. S., Souto, P. C. \& Bezerra, D. M. 2008. Deposição de serrapilheira em área de Caatinga na RPPN "Fazenda Tamanduá", Santa Terezinha-PB. Revista Caatinga, 21(2).

Apolinário, V. X. O., Dubeux, J. C. B., Mello, A. C. L., Vendramini, J. M. B., Lira, M. A., Santos, M. V. F. \& Muir, J. P. 2014. Litter Decomposition of Signalgrass Grazed with Different Stocking Rates and Nitrogen Fertilizer Levels. Agronomy Journal, 106, 622627.

Araújo, E. A. d., Ker, J. C., Mendonça, E. d. S., Silva, I. R. d. \& Oliveira, E. K. 2011. Impacto da conversão floresta - pastagem nos estoques e na dinâmica do carbono e substâncias húmicas do solo no bioma Amazônico. Acta Amazonica, 41, 103-114.

Assefa, D., Rewald, B., Sandén, H., Rosinger, C., Abiyu, A., Yitaferu, B. \& Godbold, D. L. 2017. Deforestation and land use strongly effect soil organic carbon and nitrogen stock in Northwest Ethiopia. CATENA, 153, 89-99.

Balbinot Junior, A. A., Moraes, A. d., Veiga, M. d., Pelissari, A. \& Dieckow, J. 2009. Integração lavoura-pecuária: intensificação de uso de áreas agrícolas. Ciência Rural, 39, 1925-1933.

Barcellos, A. d. O., Ramos, A. K. B., Vilela, L. \& Martha Junior, G. B. 2008. Sustentabilidade da produção animal baseada em pastagens consorciadas e no emprego de leguminosas exclusivas, na forma de banco de proteína, nos trópicos brasileiros. Revista Brasileira de Zootecnia, 37, 51-67.

Braga, G. 2006. Contribuição da pastagem para o sequiestro de carbono. Simpósio sobre o manejo de pastagem, 23, 271-296.

Carneiro, W. J. d. O., Silva, C. A., Muniz, J. A. \& Savian, T. V. 2013. Mineralização de nitrogênio em latossolos adubados com resíduos orgânicos. Revista Brasileira de Ciência do Solo, 37, 715-725.

Costa, K. d. P., de Oliveira, I. \& FAQUIN, V. 2006. Adubação nitrogenada para pastagens do gênero Brachiaria em solos do Cerrado.
Embrapa Arroz e Feijão-Documentos (INFOTECA-E).

Costa, O. V., Cantarutti, R. B., Fontes, L. E. F., Costa, L. M. d., Nacif, P. G. S. \& Faria, J. C. 2009. Estoque de carbono do solo sob pastagem em área de tabuleiro costeiro no sul da Bahia. Revista Brasileira de Ciência do Solo, 33(5).

Dias-Filho, M. 2006. Degradação e recuperação de pastagens. In: Pedreira, C. G. S., Moura, J. C., Silva, S. C. \& Faria, V. P. (ed.). As pastagens e o meio ambiente. Fealq, Piracicaba, São Paulo, Brasil.

Dias-Filho, M. B. 2014. Diagnóstico das pastagens no Brasil. Embrapa Amazônia Oriental-Documentos (INFOTECA-E).

Dubeux Júnior, J., Lira, M. d. A., Santos, M. d. \& Cunha, M. d. 2006. Fluxo de nutrientes em ecossistemas de pastagens: impactos no ambiente e na produtividade. Simpósio sobre o Manejo da Pastagem, 23, 439-506.

Dubeux Júnior, J., Sollenberger, L., Mathews, B., Scholberg, J. \& Santos, H. 2007. Nutrient cycling in warm-climate grasslands. Crop Science, 47(3), 915-928.

Dubeux Júnior, J. C. B., Sollenberger, L. E., Vendramini, J. M. B., Interrante, S. M. \& Lira, M. A. 2014. Stocking Method, Animal Behavior, and Soil Nutrient Redistribution: How are They Linked? Crop Science, 54, 2341-2350.

Maillard, É., McConkey, B. G. \& Angers, D. A. 2017. Increased uncertainty in soil carbon stock measurement with spatial scale and sampling profile depth in world grasslands: A systematic analysis. Agriculture, Ecosystems \& Environment, 236, 268-276.

Maluf, H. J. G. M., Soares, E. M. B., Silva, I. R. d., Neves, J. C. L. \& Silva, L. d. O. G. 2015. Decomposição de resíduos de culuras e mineralização de nutrientes em solo com diferentes texturas. Revista Brasileira de Ciência do Solo, 39, 1681-1689.

Sadeghpour, A., Jahanzad, E., Esmaeili, A., Hosseini, M. B. \& Hashemi, M. 2013. Forage yield, quality and economic benefit of intercropped barley and annual medic in semiarid conditions: Additive series. Field Crops Research, 148, 43-48.

Salton, J. C., Mielniczuk, J., Bayer, C., Fabrício, A. C., Macedo, M. C. M. \& Broch, D. L. 2011. Teor e dinâmica do carbono no solo em 
sistemas de integração lavoura-pecuária. Pesquisa Agropecuária Brasileira, 46(10), 1349-1356.

Saraiva, F. M. 2010. Ciclagem de nutrientes em pastagens de gramíneas tropicais manejadas sob diferentes intensidades de pastejo. $73 \mathrm{p}$., Dissertação (Mestrado) - Universidade Federal Rural de Pernambuco, Recife.

Silva, A. B., Lira Junior, M. A., Dubeux Junior, J. C. B., Figueiredo, M. V. B. \& Vicentin, R. P. 2013. Estoque de serapilheira e fertilidade do solo em pastagem degradada de Brachiaria decumbens após implantação de leguminosas arbustivas e arbóreas forrageiras. Revista Brasileira de Ciência do Solo, 37(2).

Silva, C. J. d., Sanches, L., Bleich, M. E., Lobo, F. d. A. \& Nogueira, J. d. S. 2007. Produçao de serrapilheira no cerrado e floresta de transiçao Amazônia-Cerrado do Centro-Oeste Brasileiro. Acta Amazonica, 37(4), 543-548.

Silva, H. M. S., Dubeux, J. C. B., Santos, M. V. F., Lira, M. A. \& Muir, J. P. 2012. Signal grass litter decomposition rate increases with inclusion of calopo. Crop science, 52(3), 14161423.

Silva, L. C. \& Rao, T. V. 2006. Avaliação de métodos para estimativa de coeficientes da cultura de amendoim. Revista Brasileira de Engenharia Agrícola e Ambiental, 10(01), 128-131.

Souza, E. D., Costa, S. E. V. G. A., Anghinoni, I., Carvalho, P. C. F., Andrigueti, M. \& Cao, E. 2009. Estoques de carbono orgânico e de nitrogênio no solo em sistema de integração lavoura-pecuária em plantio direto, submetido a intensidades de pastejo. Revista Brasileira de Ciência do Solo, 33(6).

Teixeira, V., Dubeux, J., de Mello, A., Lira, M., Saraiva, F. \& dos Santos, M. 2012. Herbage mass, herbage rejection, and chemical composition of signalgrass under different stocking rates and distances from dung pads. Crop science, 52(1), 422-430.

Teixeira, V. I. 2010. Ciclagem de nutrientes em pastagens de Brachiaria decumbens Stapf. sob diferentes lotações animais. 120p., Tese (Doutorado) - Universidade Federal Rural de Pernambuco, Recife.

Troeh, F. R. \& Thompson, L. M. 2007. Solos $e$ fertilidade do solo. Andrei, São Paulo, SP, Brasil.

Vendramini, J., Dubeux Jr, J. C. \& Silveira, M. L. 2014. Nutrient cycling in tropical pasture ecosystems. Revista Brasileira de Ciências Agrárias, 9(2).

Vendramini, J. M. B., Silveira, M. L. A., Dubeux Jr., J. C. B. \& Sollenberger, L. E. 2007. Environmental impacts and nutrient recycling on pastures grazed by cattle. Revista Brasileira de Zootecnia, 36, 139-149.

Vitor, C. M. T., Fonseca, D. d., Cóser, A. C., Martins, C. E., Nascimento Júnior, D. \& Ribeiro Júnior, J. 2009. Produção de matéria seca e valor nutritivo de pastagem de capimelefante sob irrigação e adubação nitrogenada. Revista Brasileira de Zootecnia, 38(3), 435442.

Xavier, D. F., da Silva Lédo, F. J., de Campos Paciullo, D. S., Pires, M. d. F. Á. \& Boddey, R. M. 2012. Dinâmica da serapilheira em pastagens de braquiária em sistema silvipastoril e monocultura. Pesquisa Agropecuária Brasileira, 46(10), 1214-1219.

Article History:

Received 23 March 2018

Accepted 12 April 2018

Available online 15 May 2018

License information: This is an open-access article distributed under the terms of the Creative Commons Attribution License 4.0, which permits unrestricted use, distribution, and reproduction in any medium, provided the original work is properly cited. 